\title{
Simulating the Production of Medical Radioisotopes in a Fast Thorium-Cycle ADS with SERPENT
}

\author{
Ranjana Nath-M \\ International Thorium Energy Committee (iThEC), Geneva, Switzerland \\ Email: ranjana.magnani@gmail.com
}

How to cite this paper: Nath-M, R. (2021) Simulating the Production of Medical Radioisotopes in a Fast Thorium-Cycle ADS with SERPENT. World Journal of Nuclear Science and Technology, 11, 43-64. https://doi.org/10.4236/wjnst.2021.111003

Received: November 4, 2020

Accepted: January 26, 2021

Published: January 29, 2021

Copyright $\odot 2021$ by author(s) and Scientific Research Publishing Inc. This work is licensed under the Creative Commons Attribution International License (CC BY 4.0).

http://creativecommons.org/licenses/by/4.0/

\section{(c) (i) Open Access}

\begin{abstract}
Radiopharmaceuticals are used in nuclear medicine for diagnostic or therapeutic acts. The short decay half-lives of medical radioisotopes, especially those used for diagnostics, imply that they should be produced continuously and transported as quickly as possible to the medical units where they are used. Neutron-rich medical radioisotopes are generally produced in research reactors, like technetium-99m, lutetium-177, holmium-166 and iodine-131. On the other hand, proton-rich radioisotopes are produced via reactions with charged particles from accelerators like fluorine-18, gallium-67, iodine-123 and thallium-201. Beside this, innovative nuclear reactors are advocated as solutions to the issues of nuclear waste production and proliferation threats. Fast neutron, thorium-cycle and accelerator-driven subcritical (ADS) reactors are some of the most promising of them, proposed as safer fuel breeders and "waste burners". This article examines the use of a fast thorium-cycle ADS with liquid lead-bismuth eutectic coolant for the production of molybdenum-99/technetium-99m and lutetium-177. Burnup simulation has been made with the Monte-Carlo (MC) code SERPENT. It is demonstrated that MC codes can advantageously be used to determine the optimal irradiation time for a given radioisotope in a realistic reactor core. It is also shown that fast thorium-cycle ADS is an economical option for the production of medical radioisotopes.
\end{abstract}

\section{Keywords}

Medical Radioisotopes, Molybdenum-99, Technetium-99m, Lutetium-177, Fast Reactor, Thorium Cycle, Subcritical Reactor, ADS, Spallation, Activation, Burnup, SERPENT 


\section{Introduction}

Medical radioisotopes are used for the diagnosis and treatment of several illnesses. They are specifics medicines relying on the injection into the patient of a radionuclide, combined with a biologically active molecule to form a compound called "radiopharmaceutical". This radiopharmaceutical preferentially localizes specific organs [1], cells or tumors, either for imaging/diagnosis purpose, or for therapeutic purpose. These radionuclides have generally short half-lives (no longer than hours or days), in order to reduce the exposition of the patient to harmful radiations. This is why they should be transported rapidly from the place where they are produced to the hospitals which will use them. Currently, there are in Europe over 12 million medical procedures using radioisotopes. About $90 \%$ of radioisotopes are used for diagnostic purposes and 10\% for therapies [2] [3].

\subsection{Diagnosis Radioisotopes}

Imaging based on a radionuclide provides irreplaceable data on physiological function and metabolism, with respect to other classical techniques like echography or simple X-ray radiography. It can detect and give specific information about rapidly growing tissues such as tumors, metastasis, and is largely used in oncology [4]. The ideal radioisotope for nuclear imaging typically emits $\gamma$ rays, with energies from $100 \mathrm{keV}$ to $300 \mathrm{keV}$, traversing the human body without sensible attenuation and are easily detected by gamma sensitive cameras. The radionuclide should have a short half-life, a few hours, to reduce the irradiation of the patient. But sometimes a longer half-life is desirable for tracking longer biological processes.

One of the most current medical investigation is the single-photon emission computed tomography (SPECT) [1]. The injected radioisotope decays with the emission of a single $\gamma$ photon, by inner electron capture or by isomeric transition. Radiations are captured by scintillation with a camera, which turns around the patient and is used to reconstruct a 3D image by computer. Technetium-99m $\left({ }^{99 \mathrm{~m}} \mathrm{Tc}\right)$ is the most widely used radioisotope for this kind of medical examination, used in more that $80 \%$ of all nuclear medicine procedures worldwide, due to the low energy $\gamma$ radiation, limiting the dose to the patient. Tc is chemically well-suited to compose different tracers, and with a half-life of 6 hours ${ }^{99 \mathrm{~m}} \mathrm{Tc}$ loses rapidly its activity inside the patient's body. A more advanced technique, positron emission tomography (PET), relies on a radionuclide which decays by production of a positron which annihilates and emits a pair of $\gamma$ photons with opposite directions at $511 \mathrm{keV}$ each. The simultaneous detection of these two photons allows a very precise $3 \mathrm{D}$ reconstruction by coincidence. The most common PET isotopes are ${ }^{18} \mathrm{~F}$ (in ${ }^{18} \mathrm{~F}$-FDG radiopharmaceutical), ${ }^{11} \mathrm{C},{ }^{13} \mathrm{~N}$ and ${ }^{15} \mathrm{O}$ of which use are growing in oncology, neurology and cardiology.

\subsection{Therapeutic Radioisotopes}

Therapeutics require decays which produce highly ionizing particles to destroy 
nearby malignant cells with a high dose. But it is primordial that these particles are promptly stopped at short distances from their emission point in order to spare healthy tissues. The most used therapeutic radionuclides are $\beta$ emitters, Auger electron emitters and $\alpha$ emitters. Auger radiation consists in the filling of an inner-shell vacancy of the atom, resulting from the absorption of an electron of that inner-shell by a proton, and followed by the emission of another electron from this atom. A choice of the radionuclide is made to match at best the type of lesion to treat. $\beta$ particles, with action ranges of approximately $1 \mathrm{~mm}$, are well-suited to large lesions or tumors. The very short-range of Auger electrons $(\sim 10 \mu \mathrm{m})$ makes them ideal to target small cancer metastases disseminated in the body [5].

\section{Production of Radioisotopes}

Neutron-rich radioisotopes (e.g. ${ }^{99 \mathrm{~m}} \mathrm{Tc}$, lutetium-177 - ${ }^{177} \mathrm{Lu}$, holmium-166 ${ }^{166} \mathrm{Ho}$, iodine-131 - ${ }^{131} \mathrm{I}$, etc.) are generally produced in research fission reactors, providing high neutron flux and often using highly-enriched uranium (U) fuels (HEU). This is the case for molybdenum-99 $\left({ }^{99} \mathrm{Mo}\right)$, used as generator of ${ }^{99 \mathrm{~m}} \mathrm{Tc}$, for which the use of HEU poses proliferation concerns [2]. These isotopes often undergo beta-particle emission and are mostly used in nuclear medicine for oncology. This is called "activation" of the proper precursor, which absorbs one neutron and transmutes into the target radionuclide. The precursor material is often sealed in special capsules, pneumatically or hydraulically inserted into the reactor core. The precursor material is then totally isolated from the reactor's nuclear material, and does not impact the chain-reaction beside absorbing a negligible part of the neutrons.

Proton-rich (or neutron-deficient) radioisotopes (e.g. fluorine-18 $-{ }^{18} \mathrm{~F}$, gallium-67 - ${ }^{67} \mathrm{Ga}$, iodine-131 - ${ }^{123} \mathrm{I}$ and thallium-201 - ${ }^{201} \mathrm{Tl}$, etc.) are produced using accelerated charged particles, usually in cyclotrons, synchrotons or LINAC's [6]. They use generally a proton beam to irradiate a precursor of the target radioisotope. Used for neutron-deficient radioisotopes, proton irradiation could be used also to produce neutron-rich nuclides through spallation which "converts" the proton flux into a neutron flux. On the other hand, nuclear reactors provide only neutron flux and are not suited to generate neutron-deficient isotopes.

Accelerators have some advantages over reactors: less radioactive waste, no proliferation risk, easier operation of the equipment and easier decommissioning. They produce nuclides with higher specific activity and less impurities because they offer the possibility to tune the energy window of the irradiating beam to better match the precursor's cross-section. By generating often monoisotopic nuclide, they allow easier chemical or physical techniques for separation. The principal drawback of accelerators is their lower production yield compared to reactors. They also demand sometimes enriched (thus more expensive) targets for the production of a sufficient concentration of the desired radioisotope. And of course, an important point to mention is that while reactors 
can, in principle, generate power at the same time, this is not the case for accelerator-only radioisotope generator.

\subsection{Production Yield for Reactor-Produced Radioisotopes}

The production of a radioisotope from a precursor results from the equilibrium between the induced activity resulting from precursor's nuclei capturing incident neutrons, and the reduction of the radioisotope's nuclei number of neutrons due to their $\beta$ decay. It is possible to approximate the process formally. In practice however, for realistic calculation, a number of other parameters should also be taken into account:

- The target self-shielding effect;

- The reactor power variation;

- The flux depression due to adjacent samples in the reactor;

- Target burnup over time;

- Destruction of the produced radionuclide due to subsequent neutron captures.

Also, irradiating for a too long amount of time can only add potential impurities, since the desired radioisotope is of short half-life while most of impurities have long half-lives. Other factors determining radioisotope production include:

- Neutron flux and energy distribution;

- Target material characteristics and quantity;

- The cross-section for activation from the used precursor.

The best way to calculate the production of a radio-isotope for a specific reactor design is to perform simulation with a good Monte-Carlo (MC) code, capable of performing burnup calculations like SERPENT. This uses nuclear data which have been constituted over decades from numerous laboratory experiments.

\subsection{Direct Neutron Activation}

Direct neutron activation, also named the "radiative route", produces the radioisotope by capture of thermal or epithermal neutrons by the precursor's nuclei, which react by prompt emission of $\gamma$ rays. This is the (n, $\gamma$ ) activation route. With this route the target is not entirely transformed, resulting in the presence of a considerable amount of residual target atoms, named the "carrier", in the product. Separating the radioisotope from the carrier is not possible since they are isotopes of the same element! Therefore high neutron fluxes and high precursor cross-sections are desirable, in order to obtain higher specific activity with lower levels of carrier. Additionally, impurities in the target suffer neutron activation too, potentially resulting into more radioactive impurities in the product. Precursors of very high chemical purity is usually an essential requirement. Isotopically enriched precursors are often necessary too to increase the radioisotope specific activity and purity. Table 1 summarizes a few examples of the direct activation route. 
Table 1. Examples of medical radioisotope generated by the direct activation route $(\mathrm{n}, \gamma)$, where elements are: Ho: holmium; Lu: lutetium; Au: gold.

\begin{tabular}{cccc}
$(\mathrm{n}, \boldsymbol{\gamma})$ Activation & Precursor & Product radioisotope & Half-life (days) \\
\cline { 2 - 3 } & ${ }^{165} \mathrm{Ho}$ & ${ }^{166} \mathrm{Ho}$ & 1.1 \\
${ }^{176} \mathrm{Lu}$ & ${ }^{177} \mathrm{Lu}$ & 6.68 \\
${ }^{197} \mathrm{Au}$ & ${ }^{198} \mathrm{Au}$ & 2.7 \\
\hline
\end{tabular}

\section{Case of the Lutetium-177 by Direct Activation}

Lutetium-177 $\left({ }^{177} \mathrm{Lu}\right)$ is used for the treatment of metastatic endocrine cancers, in particular prostrate carcinomas. This radioactive isotope is bound to an antibody specific to the maligned cells. This radionuclide is produced by the direct activation route $(n, \gamma)$, as given in Equation (1).

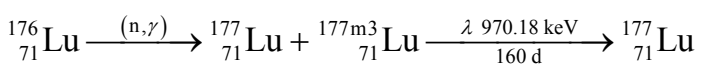

where $\mathrm{Lu}$ is the chemical element (here lutetium), with its atomic number $\mathrm{Z}$ (lower number) and atomic mass $\mathrm{A}$ (upper number); $\mathrm{A}=177 \mathrm{~m} 3$ is a $3^{\text {rd }}$ excited nuclear isomeric state. Above the arrows are expressed: the activation route $($ here $(\mathrm{n}, \gamma)$ ) and the main decay radiation(s) (here $\gamma$ ) with energy. Under arrows is given the half-life of radioisotope, in days (d) or in hours (h). The production can be made directly from natural $\mathrm{Lu}$ [7], although it has only a small fraction of ${ }^{176} \mathrm{Lu}$ with a $2.59 \%$ ratio, thanks to the high cross-section of ${ }^{176} \mathrm{Lu}$ with respect to neutrons with 2100 barns. A more efficient way to produce ${ }^{177} \mathrm{Lu}$ is to first enrich natural $\mathrm{Lu}$ at $60 \%$ or more with the ${ }^{176} \mathrm{Lu}$ isotope, increasing the production yield and reducing impurities. Note however the production of ${ }^{177 \mathrm{~m}} \mathrm{Lu}$, which undergoes isomeric $\gamma$ decay into ${ }^{177} \mathrm{Lu}$ with a long half-life of 160 days: this is an undesirable impurity and waste. Fortunately, this ${ }^{177 \mathrm{~m}} \mathrm{Lu}$ constitutes only $0.01 \%$ of the produced radioisotope inventory. Then ${ }^{177} \mathrm{Lu}$ decays inside the patient's body (hopefully... inside malign cells) according to Equation (2).

$$
{ }_{71}^{177} \mathrm{Lu} \stackrel{\beta^{-} 496.8,385,249,174 \mathrm{keV}}{6.65 \mathrm{~d}}{ }^{177 \mathrm{~m}} \mathrm{Hf}+{ }_{71}^{177} \mathrm{Hf}
$$

\subsection{Neutron Activation Followed by $\beta$-Decay}

In this mode of activation, the precursor is first activated by the (n, $\gamma$ ) route, resulting into an intermediate short-live radionuclide, as a secondary intermediate precursor. The latter undergoes a $\beta$ decay resulting into the final radioisotope of interest. The whole process is denoted as $(\mathrm{n}, \gamma \rightarrow \beta)$ route. In general, the desired product can be separated from the initial element (and the intermediate precursors) since it is another element chemically different from its precursor (with a different $Z$ ). Of course, an efficient chemical processing should exist to make this radioisotope attractive. The result is with very high specific activity radioisotope, and generally carrier-free. The optimum irradiation time needed to reach the most optimal yield results from the half-life of the intermediate precursor. In some cases, the product of the $\beta$ decay from the intermediate pre- 
Table 2. Examples of medical radioisotope generated by the activation followed by beta decay route (n, $\gamma \rightarrow \beta$ ), where elements are: Mo: molybdenum; Tc: technetium; Te: tellurium; I: iodine; Dy: dysprosium; Ho: holmium; Yb: ytterbium; Lu: lutetium; Pt: platinum; Au: gold.

\begin{tabular}{ccccc}
\hline $\begin{array}{c}\left.\text { (n, } \gamma \rightarrow \beta^{-}\right) \\
\text {Activation }\end{array}$ & Precursor & $\begin{array}{c}\text { Intermediate } \\
\text { radioisotope }\end{array}$ & $\begin{array}{c}\text { Product } \\
\text { radioisotope }\end{array}$ & Half-life (days) \\
\hline & ${ }^{98} \mathrm{Mo}$ & ${ }^{99} \mathrm{Mo}$ & ${ }^{99 \mathrm{~m}} \mathrm{Tc}$ & 0.25 \\
& ${ }^{130} \mathrm{Te}$ & ${ }^{131} \mathrm{Te}$ & ${ }^{131} \mathrm{I}$ & 8.02 \\
& ${ }^{164} \mathrm{Dy}$ & ${ }^{165,166} \mathrm{Dy}$ & ${ }^{166} \mathrm{Ho}$ & 1.1 \\
& ${ }^{176} \mathrm{Yb}$ & ${ }^{177} \mathrm{Yb}$ & ${ }^{177} \mathrm{Lu}$ & 6.68 \\
& ${ }^{198} \mathrm{Pt}$ & ${ }^{199} \mathrm{Pt}$ & $\mathrm{Au}$ & 3.14 \\
\hline
\end{tabular}

cursor further captures a neutron to form the actual target radioisotope, like the ${ }^{166} \mathrm{Dy}$ from neutron activation of enriched ${ }^{164} \mathrm{Dy}$. Some examples of radioisotopes produced by this route are listed in Table 2 .

\subsubsection{Case of the Lutetium-177 with Beta Decay}

The ${ }^{177} \mathrm{Lu}\left(\mathrm{n}, \gamma \rightarrow \beta^{-}\right)$route of Table 2 is the alternative route to direct activation $(\mathrm{n}, \gamma)$ of Table 1 [7]. In this case, ${ }^{176} \mathrm{Yb}$ is used as the initial precursor in place of ${ }^{176} \mathrm{Lu}$ [8]. But since natural $\mathrm{Yb}$ contains only $12.7 \%$ of ${ }^{176} \mathrm{Yb}$ and ${ }^{174} \mathrm{Yb}$ is the main isotope with $31.8 \%$, it would not be efficient enough to produce the desired radioisotope, and too much impurities would be generated. Therefore $\mathrm{Yb}$ should be enriched in ${ }^{176} \mathrm{Yb}$ at $99 \%$ first. Enrichment is necessary because this route has lower production yield due to smaller cross-section of ${ }^{176} \mathrm{Yb}$ regarding neutrons with 2.85 barns, than ${ }^{176} \mathrm{Lu}$. But this indirect activation route has the advantage over the direct one to avoid the production of ${ }^{177 \mathrm{~m}} \mathrm{Lu}$ with its half-life of 160 days. The process is given in Equation (3).

$$
{ }_{70}^{176} \mathrm{Yb} \stackrel{(\mathrm{n}, \gamma)}{\longrightarrow}{ }_{70}^{177} \mathrm{Yb} \stackrel{\beta^{-}}{{ }_{1.9 \mathrm{~d}}}{ }_{71}^{177} \mathrm{Lu}
$$

\subsubsection{Case of the Technetium-99m}

Production of ${ }^{99 \mathrm{~m}} \mathrm{Tc}$, with a 6 hours half-life, follows this $\left(\mathrm{n}, \gamma \rightarrow \beta^{-}\right)$route. 6 hours half-life is a far too short half-time for the transport of this radionuclide to its point of use. Fortunately, the intermediate precursor, ${ }^{99} \mathrm{Mo}$, has a rather long half-life of 2.75 days, making its supply chain much more manageable. Consequently, ${ }^{99} \mathrm{Mo}$ is actually sent to the hospital and decays there, conditioned in a "technetium-99m generator", i.e. a device where a ${ }^{99 \mathrm{~m}} \mathrm{Tc}$ pertechnetate solution is eluted from ${ }^{99}$ Mo molybdate bound to a chromatographic substrate. The common procedure for the ${ }^{99} \mathrm{Mo} /{ }^{99 \mathrm{~m}} \mathrm{Tc}$ is typically of two shipments a week.

The intermediate precursor is obtained by activation of the ${ }^{98}$ Mo present in natural Mo, with a ratio of $24 \%$. This ratio is considered to be sufficient and natural Mo is generally not enriched. The activation and decay chain are given in Equation (4):

$$
{ }_{42}^{98} \mathrm{Mo} \stackrel{(\mathrm{n}, \gamma)}{\longrightarrow}{ }_{42}^{99} \mathrm{Mo} \stackrel{\beta^{-} 1.216 \mathrm{MeV}}{\longrightarrow 65.94 \text { hours }}{ }^{99 \mathrm{~m}} \mathrm{Tc}
$$


Then ${ }^{99 \mathrm{~m}} \mathrm{Tc}$ decays into ${ }^{99} \mathrm{Tc}$, allowing medical examination. The latter, still unstable but with a very long half-life (thus negligible specific activity), decays into ${ }^{99} \mathrm{Ru}$. Decays are depicted by Equation (5):

$$
{ }_{43}^{99 \mathrm{~m}} \mathrm{Tc} \underset{6 \text { hours }}{\stackrel{\gamma 141 \mathrm{keV}}{\longrightarrow}}{ }_{43}^{99} \mathrm{Tc} \underset{211000 \text { years }}{\stackrel{\beta^{-} 249 \mathrm{keV}}{\longrightarrow}}{ }_{44}^{99} \mathrm{Ru}
$$

\subsection{The $(n, p)$ Production Reaction}

It may happen that the absorption of neutron $(n)$ triggers the emission of a proton $(p)$, a path referred to as the $(n, p)$ route. Note that cross-sections for this reaction are low. Generally, cross-sections are much higher for neutron energies between 2 and $6 \mathrm{MeV}$. This makes this route result in low yields since producing reactors are generally thermal neutron reactors. This route is much better suited for fast reactors.

Also in this case, the product nuclei require chemical separation from the large macroscopic levels of target atoms. Next Table 3 lists a few important radioisotopes made using this route.

\section{Accelerator-Driven Subcritical Reactors}

The majority of nuclear reactors are PWR and BWR, which produce significant amounts of $\mathrm{Pu}$ and of the longest-live radioactive waste, i.e. transuranic (TRU) elements and minor actinides (MA). Fast-neutron reactors have been proposed as fuel breeders to better close the nuclear fuel cycle, and as waste burners. Thorium-cycle reactors are promoted to drastically limit the production of $\mathrm{Pu}$ and other waste. Finally, accelerator-driven sub-critical (ADS) reactors are advocated to be safer and even more efficient waste-burners. One example of ADS is the MYRRHA project [9]. ADS can also be used for the production of neutron-rich radioisotopes as a result of their high neutron flux characteristics, while producing power at the same time [10]. All these qualities together can increase the value of ADS despite their added complexity with respect to critical reactors.

The reactor core of an ADS is tuned to maintain an effective criticality $k_{\text {eff }}$ around 0.96 , thus a chain reaction is impossible without an external source of neutrons. Then an additional source of neutrons is inserted inside the core to bring the "missing" neutrons and to obtain a with-source criticality $k_{0}$ close to 1 in order to sustain a chain reaction. The ADS acts as an Energy Amplifier, multiplying the energy used to bring external neutrons by a factor of 25 to 45 thanks to the so-triggered and sustained fission [11]. The most efficient way to produce

Table 3. Examples of medical radioisotope generated by the $(n, p)$ route, with elements: S: sulfur; P: phosphorus; Zn: zinc; Cu: copper; Hg: mercury; Au: gold.

\begin{tabular}{cccc}
\hline$(\boldsymbol{n}, \boldsymbol{p})$ Activation & Precursor & Product radioisotope & Half-life (days) \\
\hline${ }^{32} \mathrm{~S}$ & ${ }^{32} \mathrm{P}$ & 14.28 \\
${ }^{67} \mathrm{Zn}$ & ${ }^{67} \mathrm{Cu}$ & 2.58 \\
${ }^{199} \mathrm{Hg}$ & ${ }^{199} \mathrm{Au}$ & 3.14 \\
\hline
\end{tabular}


these external neutrons is by bombarding a heavy metal target with an intense beam of high-energy protons coming out of an accelerator. This is a process called spallation. The proton beam is usually generated by a cyclotron, a synchroton, or a LINAC (in the MYRRHA case). Examples of radioisotopes particularly well-suited to be produced inside an ADS are: ${ }^{99 \mathrm{~m}} \mathrm{Tc}$ (through ${ }^{99} \mathrm{Mo}$ ), ${ }^{129} \mathrm{I}$, ${ }^{135} \mathrm{Cs}$ isotopes, ${ }^{177} \mathrm{Lu}$ and ${ }^{166} \mathrm{Ho}$. Moreover, producing radioisotopes using commercial power reactor has economical advantages [12]. There is also an urgent need to propose new way to produce them, because many research reactors used for this purpose are usually old reactors risking definitive shutdowns, and are not replaced due to various reasons.

\section{The Proposed ADS Setup}

The modelled ADS geometry is illustrated in Figure 1. The proposed setup is a thorium-cycle (Th) fast ADS cooled by a lead-bismuth ( $\mathrm{Pb}-\mathrm{Bi}$ ) eutectic molten mixture. It is designed as a Th-loaded spent fuel burner like in the work of Barros et al. [13], except that here the spent fuel is not reprocessed.

This is a simplified model, processed by the MC code SERPENT (version 2). Such simulations have demonstrated the pertinence of ADS loaded with Th fuel [14]. Liquid metal coolant is used for fast reactors to avoid the moderation effect of water. Beside this, metals have a much better thermal conductivity than water, and can be used at higher temperature. Regarding safety they offer a larger heat reserve for mitigation of decay heat in case of accidental situations, making use of natural convection. This is because pin assemblies are generally literally plunged inside a large vessel full of liquid metal. Also, while liquid sodium (Na) is often used for fast reactors, $\mathrm{Pb}$ - $\mathrm{Bi}$ has been chosen here since it is inert with respect to oxygen, air and water, in contrast with $\mathrm{Na}$.

Th-cycle fuel is used assuming that a certain amount of fissile ${ }^{233} \mathrm{U}$ is already present with the fuel in metallic form. Pins are assembled and disposed as concentric circles inside the vessel, in a two-zone arrangement inspired from Gulik's dual-zone setup [15], except that here neutrons have a fast spectrum everywhere in the core. The vessel is cylindrical and has a $146 \mathrm{~cm}$ internal diameter for 160 $\mathrm{cm}$ internal height. The neutron source consists of a tungsten (W) spallation target placed in the center. The vacuum tube for the proton beam, coming vertically from the top of the core, is not represented on the figure for clarity.

In total there are 1424 pins of four kinds, assembled as 15 pin rings in total, and arranged as follows:

- Fuel pins: [dark and light red] pins containing ${ }^{233} \mathrm{U} / 232 \mathrm{Th}$ mixtures with two different fissile material percentages: type (a) [light red] with the highest fissile ratio: $14 \%$ of ${ }^{233} \mathrm{U}, 86 \%$ of ${ }^{232} \mathrm{Th}$; type (b) [dark red] with the lowest fissile ratio: $10 \%$ of ${ }^{233} \mathrm{U}, 90 \%$ of ${ }^{232} \mathrm{Th}$.

- Breeding pins: [purple] pins containing pure ${ }^{232} \mathrm{Th}$ only, as blanket to breed ${ }^{233} \mathrm{U}$ over time.

- Waste pins: [pink] pins coming from PWR or BWR, thus containing spent 


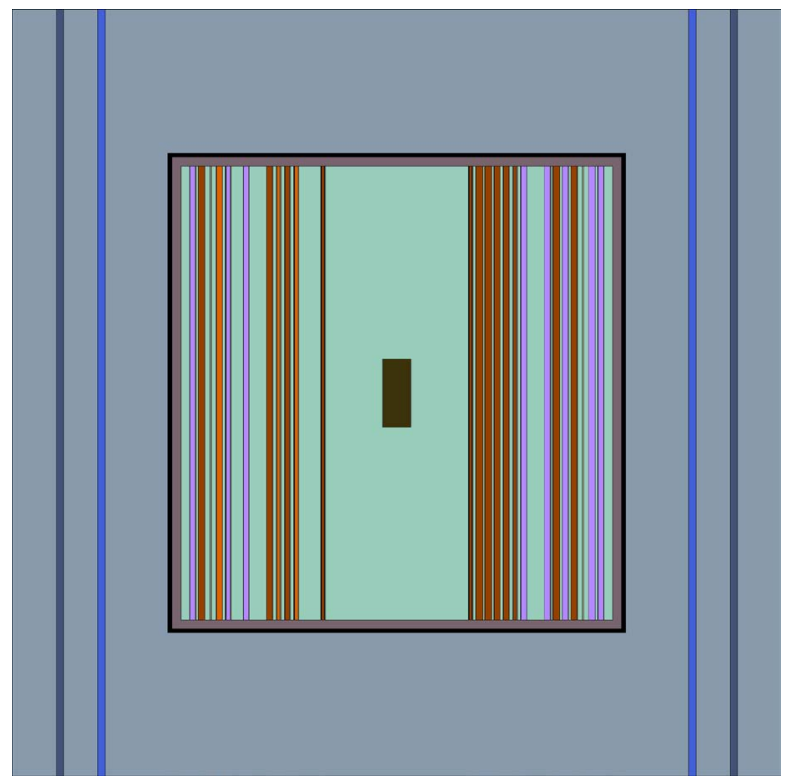

(a)

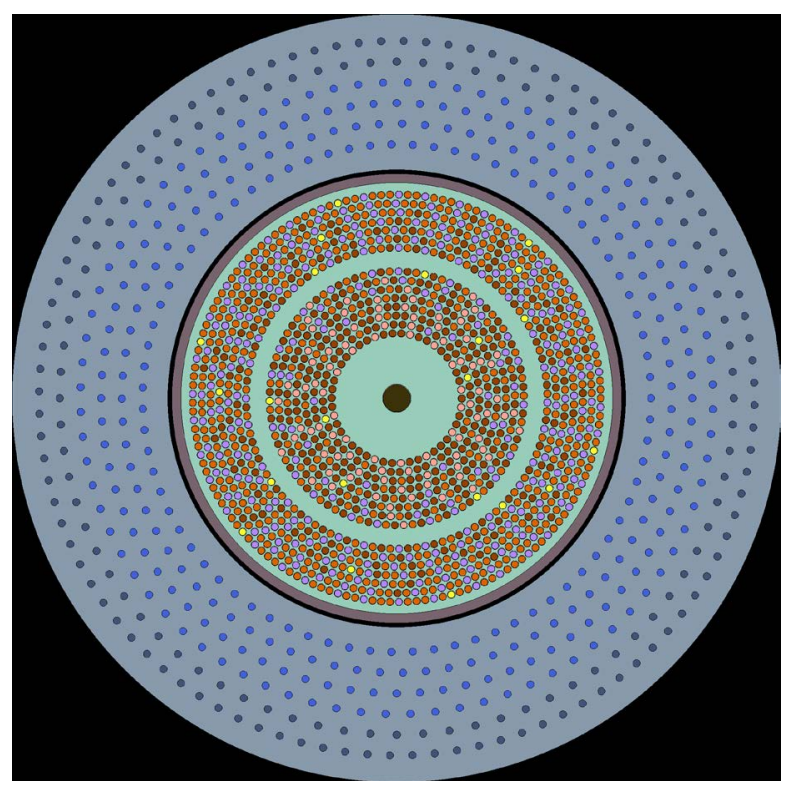

(b)

Figure 1. The ADS setup. From the center to the periphery: spallation W target [anthracite gray]; pin assembly organised in two zones: fuel pins [dark and light red]; waste pins [pink]; breeding pins [purple]; radioisotope pins [yellow]. (a) Side view; (b) Top view.

fuel with an inventory containing $95.9 \%$ of ${ }^{238} \mathrm{U}$, only $1.01 \%$ of ${ }^{235} \mathrm{U}$ (from the initial $3.5 \%$ ), the remaining being $0.95 \%$ of ${ }^{239,240,241} \mathrm{Pu} ; 0.97 \%$ of ${ }^{103} \mathrm{Rh}+$ ${ }^{133,137} \mathrm{Cs}+{ }^{143} \mathrm{Nd}$; and $0.66 \%$ of ${ }^{237} \mathrm{~Np},{ }^{238,242} \mathrm{Pu},{ }^{243} \mathrm{Am},{ }^{109} \mathrm{Ag},{ }^{134,135} \mathrm{Cs},{ }^{147} \mathrm{Pm}$, ${ }^{147,150} \mathrm{Sm}$ and ${ }^{156} \mathrm{Gd}$.

- Radioisotope pins: [yellow] pins containing the precursor of the radioisotope: either natural Mo, natural $\mathrm{Lu}$, or enriched $\mathrm{Lu}$ with $60 \%$ of ${ }^{176} \mathrm{Lu}$; from 2 to 6 pins have been placed at each pin-ring, and in total 6 rings have been selected, named: r02, r05, r08, r09, r12, and r15, with increasing distances from the center. 
Waste pins are placed in the inner zone to benefit from the higher flux of fast neutrons close to the center. Breeding pins are placed in both zones. Note that fuel pins act as breeding pins as well since they contain also ${ }^{232} \mathrm{Th}$. Fuel pins of types (a) and (b) are placed with different proportions of (a)/(b) pins within their circle-disposition, from the center to the outside, in order to achieve a static $k_{\text {eff }}$ (without neutron source) in the 0.96 - 0.97 range. Several tests with different fissile ratios for types (a) and (b) and (a)/(b) pins proportions have been made to tune $k_{\text {eff }}$

Pins have been finally assembled ring-by-ring from the center to the periphery (pin rings $\mathrm{r} 01$ to $\mathrm{r} 15$ ), as follows:

- Fuel (a) pins: progressively from $0 \%$ to $70 \%$ of all pins per ring, across the two zones;

- Fuel (b) pins: progressively from $70 \%$ to $0 \%$, across the two zones;

- Breeding pins: progressively from $0 \%$ to $22 \%$ in the inner zone, then $26 \%$ $30 \%$ in the outer zone;

- Waste pins: from $30 \%$ to $5 \%$ in the inner zone, and none in the outer zone;

- Radioisotope pins: from 1 to 6 units in rings r02, r05, r08 (inner zone) and r09, r12, r15 (outer zone).

Radioisotope pins were placed in 6 rings to select the best one, but only one ring should be eventually selected. Calculations were made for one radioisotope at a time. The proportions of (a), (b) fuel pins, breedable pins and waste pins have been arranged in order to "flatten" somehow the fission power radial distribution from the center to the periphery [10]: the inner zone, close to the center and receiving the highest neutron flux, has in majority pins with the lowest high fissile ratio [dark red]; on the other hand, the outer zone contains mostly pins with the highest fissile ratio [light red].

At the center is the $\mathrm{W}$ spallation target [dark-gray], with $9 \mathrm{~cm}$ in diameter and $24 \mathrm{~cm}$ in height. It is hit by a proton beam of 600 or $800 \mathrm{MeV}$ and $4 \mathrm{~mA}$ current. Most of spallation neutrons are emitted isotropically from the target. Spallation has been simulated using another MC code, FLUKA, using the (Generalised)IntraNuclear Cascade model ((G)INC) [16]. The resulting neutrons are read by SERPENT to model the neutrons coming out of the $\mathrm{W}$ spallation target. The neutron flux obtained is of the order of $10^{17}$ neutron/s. All pins are plunged in $\mathrm{Pb}$ - $\mathrm{Bi}$ mixture [green], the whole core being operated at the rather high temperature of $700^{\circ} \mathrm{K}\left(\sim 427^{\circ} \mathrm{C}\right)$, which is higher than for PWRs and has an impact on material cross-sections. All pins are protected by zircaloy cladding and the vessel is made of stainless Steel 304. Outside the vessel is a large concrete shielding [gray] with inserted beryllium (Be) bars [dark blue] and iron bars [dark-gray] acting as neutron reflectors.

\section{Simulation of Radioisotopes Production}

For simplicity, blanket pins containing a precursor of the desired radioisotope are identical to the other kinds of pin, using the same cladding. The production 
of ${ }^{99} \mathrm{Mo}$ and ${ }^{177} \mathrm{Lu}$ have been simulated, separately, by running SERPENT in burnup mode, as the following variants:

- Production of ${ }^{99} \mathrm{Mo}$ (intermediate precursor of ${ }^{99 \mathrm{~m}} \mathrm{Tc}$ ) by the activation of natural Mo;

- Production of ${ }^{177} \mathrm{Lu}$ by the activation of natural Lu;

- Production of ${ }^{177} \mathrm{Lu}$ by the activation of enriched $\mathrm{Lu}$ with $99 \%$ of ${ }^{176} \mathrm{Lu}$.

Nuclear used data for the simulation is the following:

- The JEFF-3.1/-3.1.1 radioactive decay data and fission yield sub-libraries;

- The ENDF/B7 DEC nuclear cross-section libraries;

- The ENDF/B7 NFY computer Index of Neutron Data.

\subsection{Setting-Up the ADS}

Before burnup calculations the ADS was first tuned to the proper criticalities. The obtained values were similar with and without the radioisotope blankets inside the core. For this step, 20 batches of 2000 neutrons have been used, resulting in the following values:

- Effective criticality: $k_{\text {eff }}=0.96727 \pm 0.00123$ (without source);

- With-source criticality: $k_{0}=1.01930 \pm 0.00698$;

- ADS multiplication factor: $\mathrm{M}=31.387 \pm 0.03882$ (Energy Amplification).

The different pin assembly compositions were chosen to limit the fissile material ratio (which does not exceed $14 \%$ of ${ }^{233} \mathrm{U}$ ). Fuel pins (a) and (b) were arranged in order to limit as much as possible the difference of average fission powers between the center and the periphery of the core. This distribution is shown in Figure 2, for each kind of pin, as function of pin ring placement from

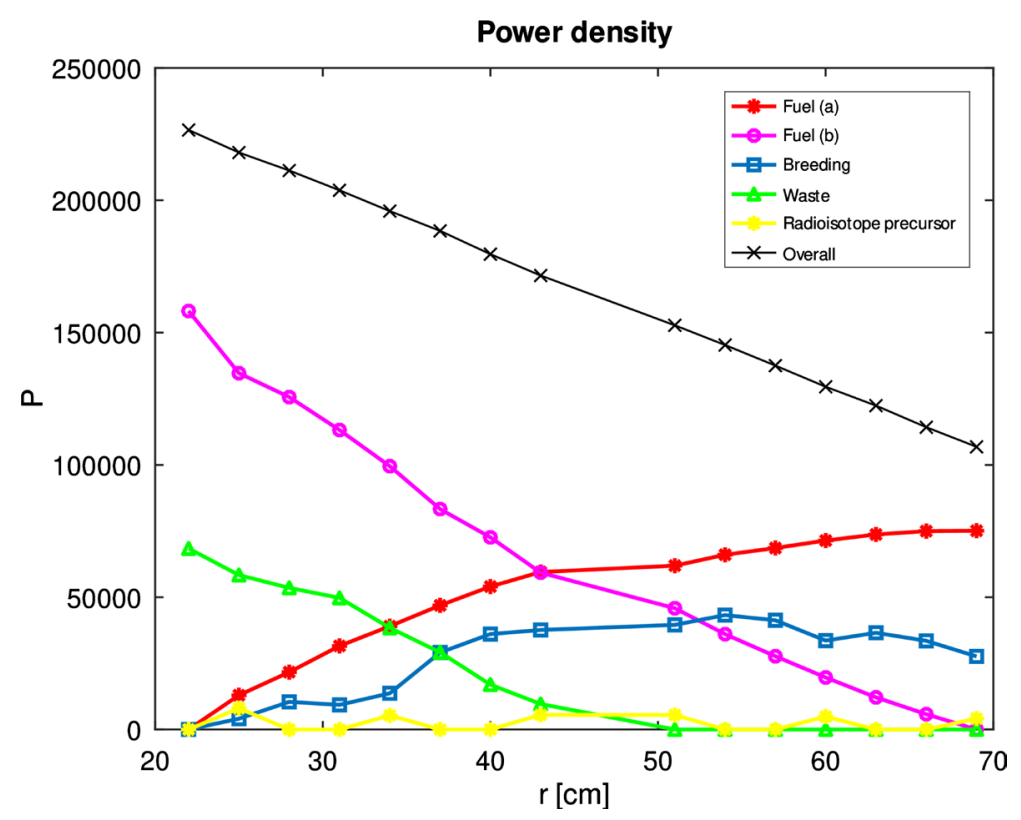

Figure 2. Average pin fission power density (in $\mathrm{W} \cdot \mathrm{m}^{-1}$ ) as function of pin ring placement (r01 to r15)/radius from the center (in $\mathrm{cm}$ ), normalised by the number of pins of each ring. Each curve is a type of pin: fuel (a) [red], fuel (b) [purple], breeding [gray blue], waste [green], and overall power density [black], radioisotope precursor [yellow]. 
r01 to r15 (or distance from the center). Power actually decreases from the center to the outer regions. This is a result form the fact that a higher proportion of fissile fuel pins ((a) and (b)) were needed close to the center to allow the system to attain the with-source criticality $k_{0} \cong 1$.

The small number of radioisotope precursor pins does not interfere significantly with the neutronic characteristics of the reactor. Additionally, neutron spectra have been plotted in Figure 3 also as function of pin ring placement, measured for radioisotope precursor pins. It is confirmed that the system operates mostly in the fast neutron regimes, with a peak around $0.5 \mathrm{MeV}$ and that the neutron flux is the highest close to the center (for pin ring r01).

\subsection{Simulating Radioisotope Activation}

The principle advantage of simulation over formal calculation, is that simulation can take into account many physical parameters that are difficult or impossible to include in calculations. They are for example: activation or destruction of various isotopes resulting from multiple subsequent neutron captures, or from decays; self-shielding inside the precursor sample. The potential drawbacks of this approach are: possible difficulty to find a tradeoff between accuracy and calculation time; how to make certain that results are quantitatively close to an actual experiment.

To simulate the production of radioisotopes from the precursors, SERPENT has been run in burnup mode, a major functionality of this MC code. Burnup calculations have been restricted to the precursor pins only. The idea is that the neutronic flux will always be kept rather steady for long periods of operating time, from months to years, by inserting fresh pins, removing older pins, modulating the accelerator intensity, etc. On the other hand, medical radioisotopes typically buildup in days or weeks at most. Of course, it should be possible to insert or remove radioisotope pins without stopping the reactor. For each simulated radioisotope production, a certain number of neighboring isotopes in the Periodic Table have been set-up in SERPENT to follow their buildup or destruction.

\subsubsection{Buildup of Molybdenum-99 from Natural Molybdenum}

Buildup of ${ }^{99}$ Mo from natural Mo has been simulated with SERPENT, over 12 days, with an interval of time $\Delta T=0.25$ day. Known elements and isotopes with $Z \pm 2$ or 3 with respect to ${ }^{98}$ Mo have been added to the inventory to track the generation of impurities. They are:

- Molybdenum isotopes: ${ }^{92,93,94,95,96,97,98,99,100}{ }_{42} \mathrm{Mo}$;

- Technetium isotopes: ${ }^{97,98,99,99 m} \mathrm{~m}$ Tc ;

- Ruthenium isotopes: ${ }^{96,98,99,100,101,102,104,106} \mathrm{Ru}$;

- Rhodium isotopes: ${ }^{101,102 \mathrm{~m}, 103}{ }_{45} \mathrm{Rh}$;

- Niobium isotopes: ${ }^{91,92,93,94} \mathrm{Nb}$;

- Zirconium isotopes: ${ }^{90,91,92,93,94,95,96} \mathrm{Zr}$.

Note also that natural Mo has a quite complex isotopic composition $(24.13 \%$ of ${ }^{98} \mathrm{Mo}, 16.68 \%$ of ${ }^{96} \mathrm{Mo}, 15.92 \%$ of ${ }^{95} \mathrm{Mo}, 14.84 \%$ of ${ }^{92} \mathrm{Mo}$, etc.) which can produce 

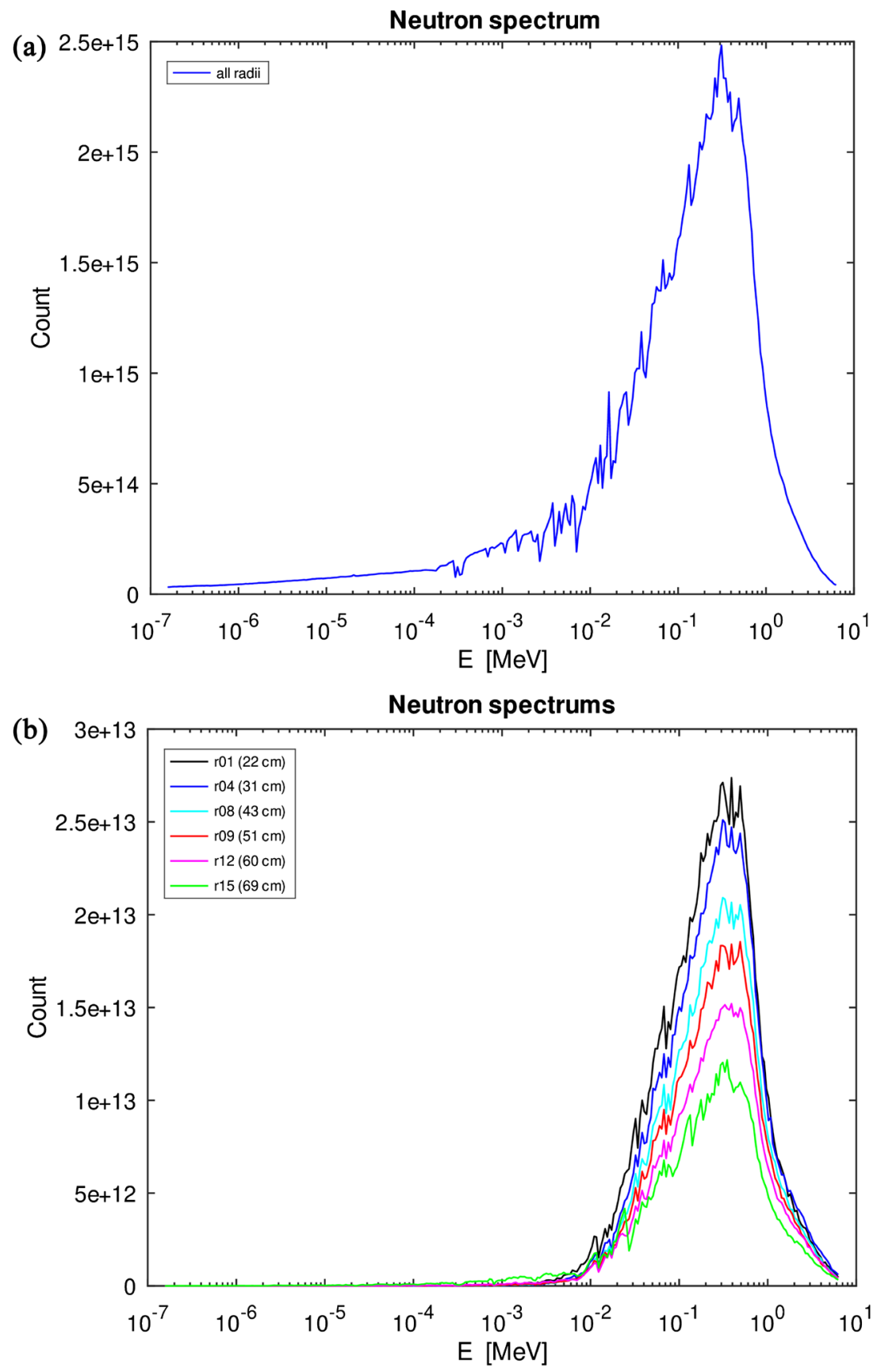

Figure 3. Neutron spectra, energy in $\mathrm{MeV}$ and counts in $\mathrm{n} / \mathrm{cm}^{3}$, measured: (a) globally for the whole reactor core; (b) at the location of radioisotope pins for each pin ring (r01 to r15)/distance from the center. (a) Global neutron spectrum; (b) Radial neutron spectra at radioisotope pins.

significant amounts of impurities.

Figure 4 depicts the buildup of ${ }^{99}$ Mo from natural Mo over 12 days, represented for the 6 assembly rings $\mathrm{r} 02$ to $\mathrm{r} 15$, where radioisotope pins have been placed. It is confirmed that ring $\mathrm{r} 02$ is the most efficient place for activation, due to the higher neutron flux close to the center. A saturation of the desired radioisotope ${ }^{99} \mathrm{Mo}$ (in concentration, (a)) is approached after 6 to 7 days of 
(a)

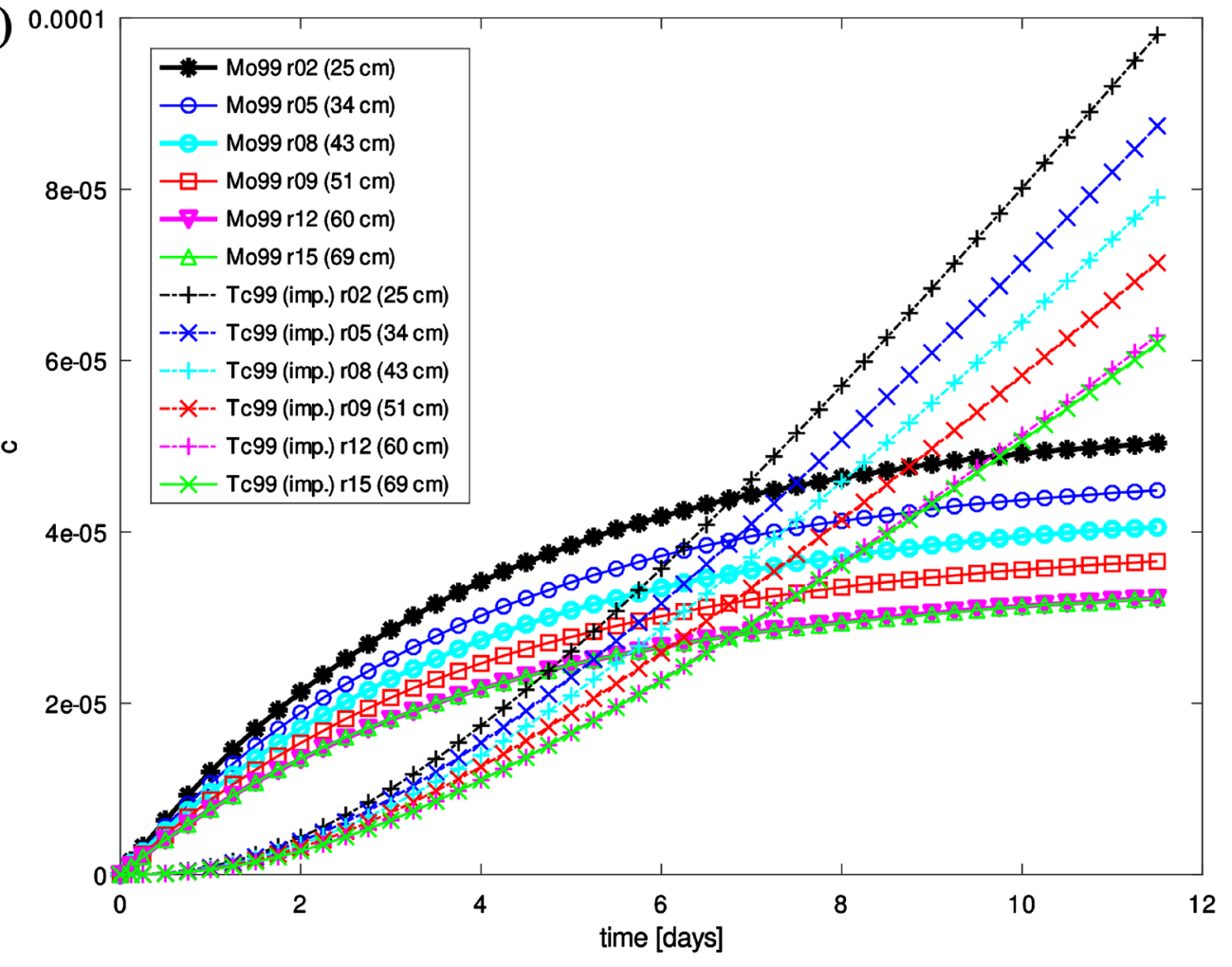

Mo99 activity/volume (r02 - r15)

(b)

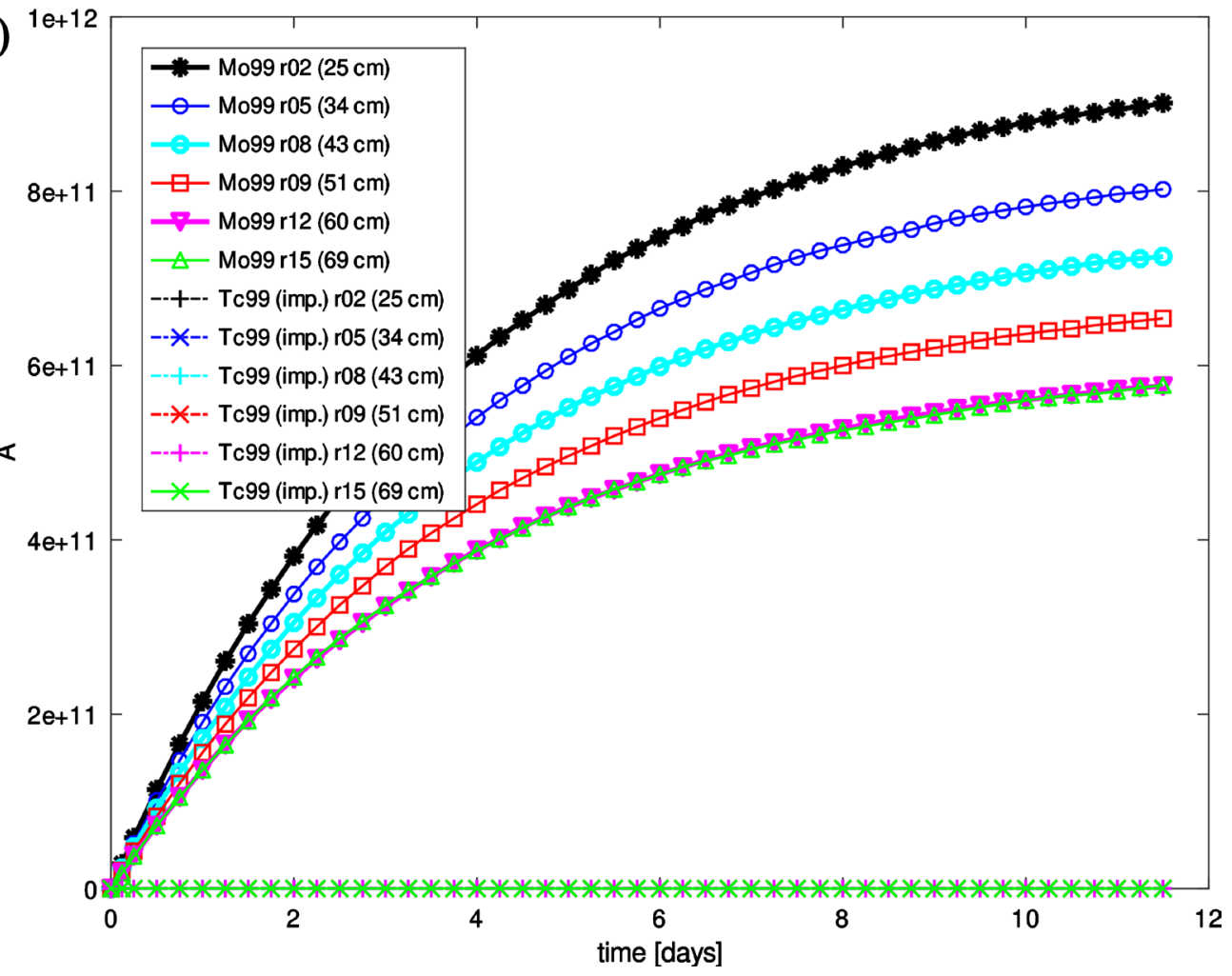

Figure 4. Buildup of ${ }^{99} \mathrm{Mo}$ (desired radioisotope) and of ${ }^{99} \mathrm{Tc}$ (impurity), as a function of pin ring placement within the core. Time is the duration of irradiation. (a) ${ }^{99} \mathrm{Mo}$ and impurities volumic concentration $\left[\mathrm{g} / \mathrm{cm}^{3}\right]$; (b) ${ }^{99} \mathrm{Mo}$ and impurities volumic activity $\left[\mathrm{Bq} / \mathrm{cm}^{3}\right]$. 
irradiation. The curve for the most important impurity, identified as ${ }^{99} \mathrm{Tc}$, is plot as well. But the concentration of this impurity always increases and goes above the concentration of ${ }^{99} \mathrm{Mo}$ after 7 days. While ${ }^{99} \mathrm{Mo}$ decays with a halftime of $65.94 \mathrm{~h}$ and progressively disappears, ${ }^{99} \mathrm{Tc}$ remains there due to its half-life of 211,100 years.

This may suggest that the blanket should be removed from the reactor after 6 days. But the same plot made regarding activity actually shows that only the desired ${ }^{99} \mathrm{Mo}$ is significant, while there is no measurable activity from impurities. Moreover, since ${ }^{99} \mathrm{Mo}$ is an intermediate precursor, and since the ${ }^{99 \mathrm{~m}} \mathrm{Tc}$ isotope (resulting from the decay of ${ }^{99} \mathrm{Mo}$ ) will be later extracted easily as a carrier-free radioisotope, the pin can be removed after 8 to 10 days.

In this setup, radioisotope blankets should be placed as close as possible to the center of the core to benefit from the highest neutron flux. The plot of Figure 5 confirms the result for pin ring r02. The ideal time of removal of the radioisotope blanket would be between 6 and 8 days.

An approximate quantitative estimation of the efficiency of the production can be made here. A typical ${ }^{99 \mathrm{~m}} \mathrm{Tc}$ generator contains from less than 1 to $20 \mathrm{Cu}$ ries $(\mathrm{Ci})$ of ${ }^{99} \mathrm{Mo}$ [17]. This represents less than $3.7 \times 10^{10}$ up to $7.4 \times 10^{11} \mathrm{Bec}-$ querels $(\mathrm{Bq})$. Considering that pins are taken out after 7 days of irradiation, one pin has an activity close $8 \times 10^{11} \mathrm{~Bq} / \mathrm{cm}^{3}$. With each pin having $608 \mathrm{~cm}^{3}$ each, one calculates that about 656 of the largest ${ }^{99 \mathrm{~m}} \mathrm{Tc}$ generators $(20 \mathrm{Ci})$, and 13,137 of the smallest ones $(1 \mathrm{Ci})$, can be produced for one single pin. This estimation looks reasonable, knowing that a few pins can be used, and despite the unavoidable loss of activity during the radioisotope shipment to the end user-assuming loss does not exceed $50 \%$.

\subsubsection{Buildup of Lutetium-177 from Natural Lutetium}

The experimented activation for ${ }^{177} \mathrm{Lu}$ is the direct activation route $(\mathrm{n}, \gamma)$ of Table $1 .{ }^{177} \mathrm{Lu}$ is the target radioisotope, therefore this route does not allow a carrier-free isotope. Consequently, ingrowth of impurities is more important here. Natural $\mathrm{Lu}$ is irradiated, knowing that the precursor is ${ }^{176} \mathrm{Lu}$ and constitutes only $2.59 \%$ of natural $\mathrm{Lu}$, while the majoritarian isotope is ${ }^{175} \mathrm{Lu}$ with a $97.41 \%$ ratio. This route can be used because ${ }^{176} \mathrm{Lu}$ has a high cross-section of 2100 barns. Then in total 40 days of activation have been simulated with SERPENT (for the best pin ring r02), because of the rather long half-time of ${ }^{177} \mathrm{Lu}$ (6.65 days), with an interval of time $\Delta T=0.5$ day. The considered elements and isotopes with $Z \pm$ 2 or 3 with respect to ${ }^{177} \mathrm{Lu}$ are the following:

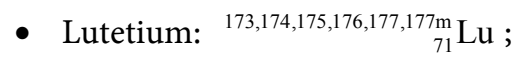

- Hafnium: $172,174,176,177,178,178 \mathrm{~m} 2,179,180,182 \mathrm{Hf}$;

- Tantalum: ${ }^{179,180,180 \mathrm{~m}, 181}{ }_{73} \mathrm{Ta}$;

- Tungsten: ${ }^{180,181,182,183,184,185,186} \mathrm{~W}$;

- Ytterbium: ${ }^{168,170,171,172,173,174,176} \mathrm{Yb}$;

- Thulium: ${ }_{69}^{169,171} \mathrm{Tm}$.

The simulation is plotted in Figure 6.

In term of concentration, several isotopes of $\mathrm{Hf}$ (hafnium) increase significantly: 
${ }^{178} \mathrm{Hf}$ becomes progressively significant, ${ }^{177} \mathrm{Hf}$ looks to overcome ${ }^{177} \mathrm{Lu}$ after approximately 14 days, and in particular ${ }^{176} \mathrm{Hf}$ 's concentration goes far beyond ${ }^{177} \mathrm{Lu}$ from the beginning! In term of activity however, impurities remain perfectly negligible over the whole irradiation duration. Strangely, the saturation of the target radioisotope is not so obvious and seems to happen later than the 40

\section{Mo99 concentration}

(a)

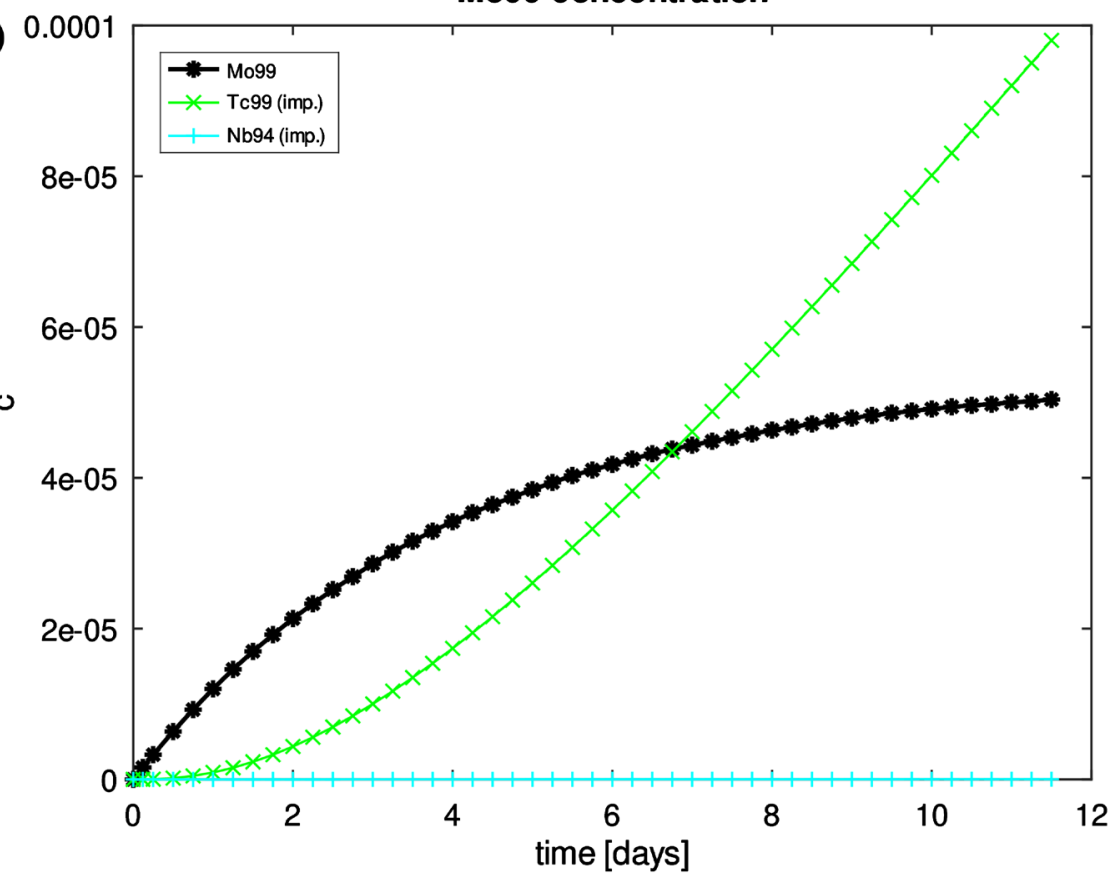

(b)

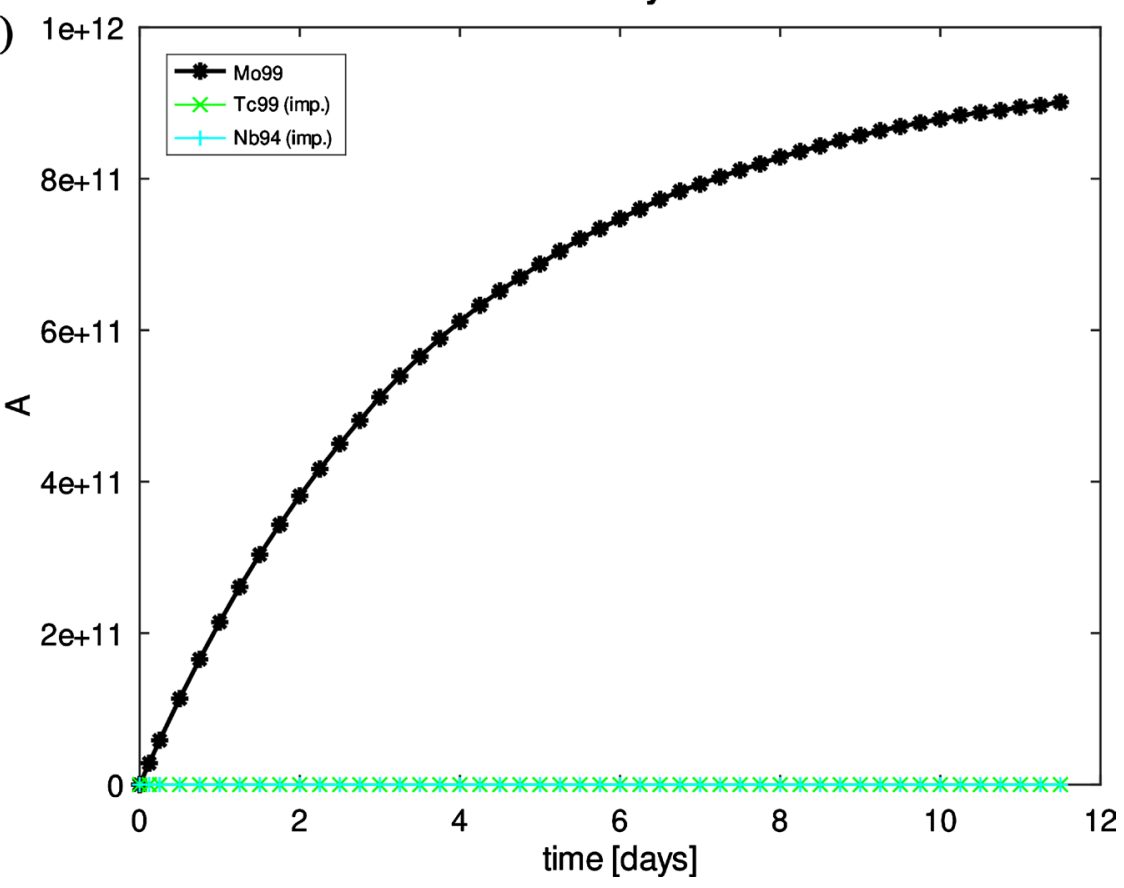

Figure 5. Buildup of ${ }^{99} \mathrm{Mo}$ (desired radioisotope) and of ${ }^{99} \mathrm{Tc}$ (impurity), for the best pin ring (r02). Time is the duration of irradiation. (a) ${ }^{99} \mathrm{Mo} /$ impurities volumic concentration $\left[\mathrm{g} / \mathrm{cm}^{3}\right] ;(\mathrm{b}){ }^{99} \mathrm{Mo} /$ impurities volumic activity $\left[\mathrm{Bq} / \mathrm{cm}^{3}\right]$. 

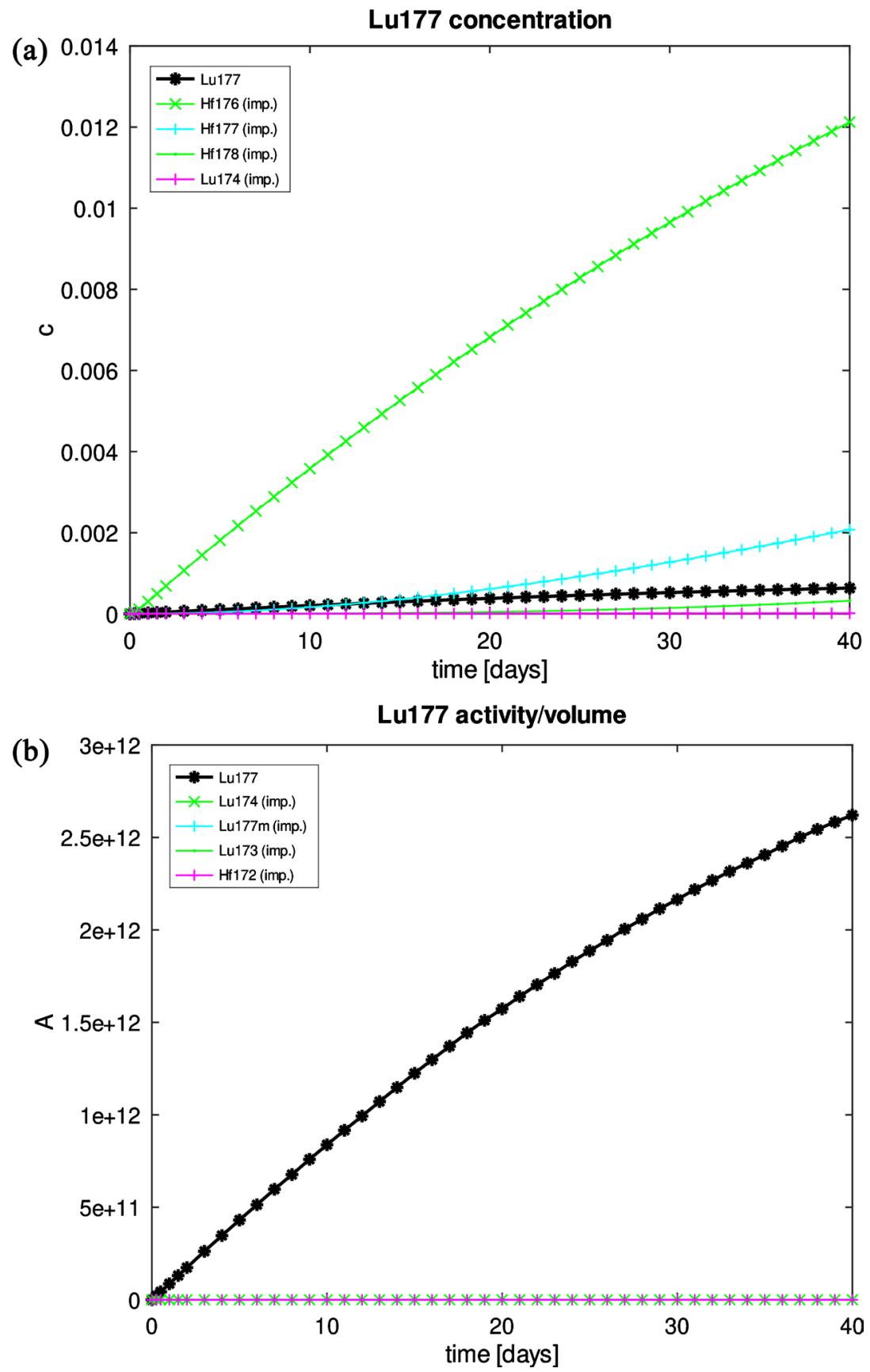

Figure 6. Buildup of ${ }^{177} \mathrm{Lu}$ (desired radioisotope) and of Hf (impurities), from natural Lu, for the best pin ring (r02). Time is the duration of irradiation. (a) ${ }^{177} \mathrm{Lu} / \mathrm{impurities}$ volumic concentration $\left[\mathrm{g} / \mathrm{cm}^{3}\right]$; (b) ${ }^{177} \mathrm{Lu} /$ impurities volumic activity $\left[\mathrm{Bq} / \mathrm{cm}^{3}\right]$.

days. However, since the product will not be carrier-free, the removal of the radioisotope blanket could be recommended before 40 days, e.g. at 15 or 20 days, to limit the concentration in ${ }^{176} \mathrm{Hf}$.

An estimation of the efficiency of the production can be made here knowing that a typical injection dose ${ }^{177} \mathrm{Lu}$ is of $200 \mathrm{mCi}$ under the form of (Peptide DOTA, Tyr) octreotate, representing $7.4 \times 10^{9} \mathrm{~Bq}$. If pins are taken out after 15 days, one pin has an activity [8] of $7.6 \times 10^{14} \mathrm{~Bq} / \mathrm{cm}^{3}$. This corresponds to 102,635 
doses per pin (for a $608 \mathrm{~cm}^{3}$ pin volume). Using a couple of pins would ensure a significant production of this isotope.

\subsubsection{Buildup of Lutetium-177 from Enriched Lutetium}

Finally, an experiment has been reconducted with lutetium, isotopically enriched with $99 \%$ of ${ }^{176} \mathrm{Lu}$ to drastically increase the production yield. Results are plotted in Figure 7. In term of concentration, the buildup of the target radioisotope is this
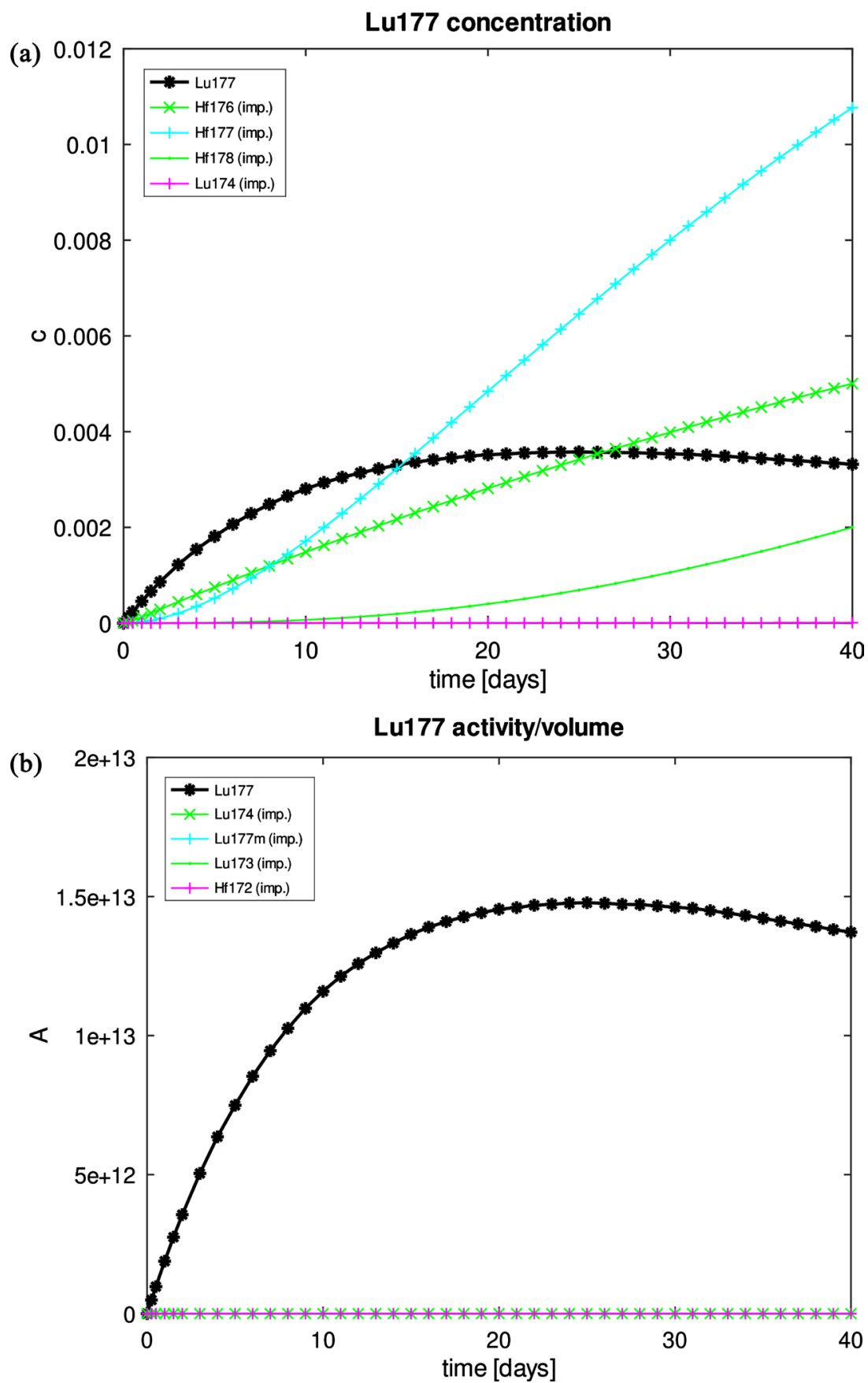

Figure 7. Buildup of ${ }^{177} \mathrm{Lu}$ (desired radioisotope) and of $\mathrm{Hf}$ (impurities), from enriched Lu with $99 \%$ of ${ }^{176} \mathrm{Lu}$, for the best pin ring (r02). Time is the duration of irradiation. (a) ${ }^{177} \mathrm{Lu} /$ impurities volumic concentration $\left[\mathrm{g} / \mathrm{cm}^{3}\right]$; (b) ${ }^{177} \mathrm{Lu} /$ impurities volumic activity $\left[\mathrm{Bq} / \mathrm{cm}^{3}\right]$. 
time clearly above the curves for all impurities up to 15 days. ${ }^{177} \mathrm{Hf}$ reaches ${ }^{177} \mathrm{Lu}$ only after 16 days, and ${ }^{176} \mathrm{Hf}$ after 27 days; ${ }^{178} \mathrm{Hf}$ builds up much more slowly. Note that ${ }^{177} \mathrm{Hf}$ is the main daughter isotope of ${ }^{177} \mathrm{Lu}$, which ingrows as a result of ${ }^{177} \mathrm{Lu}$ 's decay as soon as it is generated! But fortunately, ${ }^{177} \mathrm{Hf}$ isotope is stable. Activity of impurities remains negligible regarding activity of ${ }^{177} \mathrm{Lu}$, which is very favorable.

But the most interesting point observed is that the produced radioisotope reaches saturation after 15 - 25 days, after which it starts decreasing. The explanation of this decrease is that the target radioisotope ${ }^{177} \mathrm{Lu}$ keeps getting transmuted by capturing further neutrons and eventually get destroyed. This effect was not visible with natural $\mathrm{Lu}$ as precursor, but becomes prominent with ${ }^{176} \mathrm{Lu}$ enriched Lu. One should find the daughter isotope of this "over-activation": a good candidate is ${ }^{178} \mathrm{Hf}$ (with $\beta$ decay), of which the concentration becomes visible on plots at the end of the 40 days period.

As a conclusion, the use of enriched $\mathrm{Lu}$ as precursor drastically increases the obtained activity as expected: $\mathrm{A}=1.5 \times 10^{13} \mathrm{~Bq} / \mathrm{cm}^{3}$ after 20 days for enriched $\mathrm{Lu}$ (Figure 6(b)), versus $A=2.5 \times 1012$ after 40 days for natural Lu (Figure 7(b)). But with enriched $\mathrm{Lu}$, the ideal time to take the radioisotope blanket out of the reactor is between 15 and 20 days at the latest, before its activity starts to decrease.

An estimation of the efficiency of the production with enriched Lu with the same typical injection dose of $200 \mathrm{mCi}$ [8], representing $7.4 \times 10^{9} \mathrm{~Bq}$, results in an activity of $7.6 \times 10^{15} \mathrm{~Bq} / \mathrm{cm}^{3}$ if pins are taken out after 15 days. This corresponds to $1,026,358$ doses per pin, hence the production is 10 times more efficient than what is obtained with non-enriched $\mathrm{Lu}$.

\subsubsection{Other Options for the Lutetium-177}

SERPENT offers the mechanism to simulate also the indirect (n, $\gamma \rightarrow \beta^{-}$) route for the production of ${ }^{177} \mathrm{Lu}$ from ${ }^{176} \mathrm{Yb}$ (Table 2). But this method was not simulated, although this could certainly have brought interesting results. The reason is that nuclear data was not available for the $\mathrm{Yb}$ in any nuclear data. There are only a few literature data on the half-lives and other nuclear characteristics on the isotopes of lanthanides, and they have very high uncertainties.

\subsubsection{On the Use of Fast Neutrons}

Let's note that the production of medical radioisotopes was studied with a fast neutron reactor, resulting from this ADS design. However, neutron-rich medical radioisotopes are usually produced in thermal neutron reactors, and the majority of radioisotope require precursors having their highest cross-sections in the thermal or epidermal neutron spectrum.

In this work, fast neutrons are used, not primary for radioisotope production, but because they are suitable for an efficient waste burner. But one way to increase the production yield of radioisotopes could be to place their precursors inside moderated capsules, using for example containing capsules with graphite, carbon-rich material, or beryllium. Such simulation would probably bring inter- 
esting additional results. However, this work has demonstrated that radioisotope can be successfully produced even with a fast-neutron reactor.

\section{Conclusions}

It has been demonstrated that $\mathrm{MC}$ codes can be advantageously used to simulate the production of neutron-rich medical radioisotopes, using burnup calculations similar to those used for the calculation fuel burnup. The studied radioisotopes are: molybdenum/technetium-99m and lutetium-177, from natural lutetium and from pre-enriched lutetium. The MC codes SERPENT, with advanced burnup simulation functionalities, and FLUKA for its accurate simulation of the spallation process, have been successfully used.

MC simulation provides the data needed to estimate the optimal irradiation time of a precursor, as a function of its position within the reactor core for any geometry. The approach can even be used to determine the best removal time of a radioisotope capsule from a real running reactor, since a direct measurement of its accumulated activity is not possible. It has also been shown that a fast-neutron Th-cycle ADS can be used for the production of medical radioisotopes at a realistic rate, despite the fact that this reactor operates with fast neutrons. Moreover, producing radioisotopes in a commercial power-generating reactor is clearly an economical advantage, even if the production rate could be slightly lower than in thermal research reactors.

As a conclusion, research and modelling of the production of medical radioisotopes using new generation of nuclear reactors are further motivated by the following facts:

- There is an increasing demand for new generation of reactors, like this fast Th-cycle ADS, solving safety and waste issues, and being cost-effective;

- There is increasing pressure from governments to impose the use of lowenriched uranium (LEU) to produce radioisotopes, although historically most of them have been generated from highly-enriched uranium (HEU);

- Several reactors producing medical radioisotopes were decommissioned during these past years which created a worldwide shortage and hence the need for new production facilities.

\section{Affiliation}

The author works at iThEC-International Thorium Energy Committee (a spinoff of CERN) which promotes and studies fast thorium-fuelled ADS reactors based on Prof. Carlo Rubbia's Energy Amplifier idea [11]. Parts of the ADS concept and the production of medical radioisotopes with an ADS are studied at iThEC.

\section{Conflicts of Interest}

The author declares no conflicts of interest regarding the publication of this paper. 


\section{References}

[1] Oliver, C. (2017) Compact and Efficient Accelerators for Radioisotope Production. Proceedings of IPAC 2017, Copenhagen, 14-19 May 2017, 4824-4829. https://accelconf.web.cern.ch/ipac2017/papers/frxba1.pdf

[2] POSTNOTE (2017) Supply of Medical Radioisotopes. Parliamentary Office of Science \& Technology, 558.

https://post.parliament.uk/research-briefings/post-pn-0558

[3] OECD/NEA (2014) The Supply of Medical Radioisotopes: An Economic Diagnosis and Possible Solutions. OECD Publishing, Paris.

[4] IAEA (2006) Annex VI: Advances in Medical Radiation Imaging for Cancer Diagnosis and Treatment. Nuclear Technology Review. https://inis.iaea.org/search/search.aspx?orig_q=RN:37112943

[5] O’Donnell, R.T. (2006) Nuclear Localizing Sequences: An Innovative Way to Improve Targeted Radiotherapy. Journal of Nuclear Medicine, 47, 738-739.

[6] Owen, H.L., Ballinger, J., Buscombe, J., Clarke, R., Denton, E., Ellis, B., Flux, G., Fraser, L., Neilly, B., Paterson, A., Perkins, A.C. and Scarsbrook, A. (2014) Options for UK Technetium-99m Production Using Accelerators. Proceedings of the 5 th International Particle Accelerator Conference, Dresden, 16-20 June 2014, 2815-1818. http://cds.cern.ch/record/2158442

[7] Dash, A., Pillai, M.R.A. and Knapp Jr., F.F. (2015) Production of ${ }^{177}$ Lu for Targeted Radionuclide Therapy: Available Options. Nuclear Medicine and Molecular Imaging, 49, 85-107. https://doi.org/10.1007/s13139-014-0315-Z

[8] Dash, A., Pillai, M.R.A. and Knapp, F.F. (2015) Production of ${ }^{177}$ Lu for Targeted Radionuclide Therapy: Available Options. Nuclear Medicine Molecular Imaging, 49, 85-107. https://doi.org/10.1007/s13139-014-0315-z

[9] Sahin, H. and Abderrahim, H.A. (2012) Multi-Purpose Hybrid Research Reactor for High-Tech Applications. International Journal of Energy Research, 36, 1331-1337. https://doi.org/10.1002/er.1891

[10] Bakir, G., Selçuklu, S.B. and Yapici, H. (2016) Medical Radioisotope Production in a Power-Flattened ADS Fuelled with Uranium and Plutonium Dioxides. Science and Technology of Nuclear Installations, 2016, Article ID: 5302176. https://doi.org/10.1155/2016/5302176

[11] Carminati, F., Klapisch, R., Revol, J.P., Roche, C., Rubio, J.A. and Rubbia, C. (1993) An Energy Amplifier for Cleaner and Inexhaustible Nuclear Energy Production Driven by a Particle Beam Accelerator. CERN-AT-93-47-ET. https://cds.cern.ch/record/256520/files/at-93-047.pdf

[12] Mushtaq, A. (2012) Producing Radioisotopes in Power Reactors. Journal of Radioanalytical Nuclear Chemistry, 292, 793-802. https://doi.org/10.1007/s10967-011-1537-5

[13] Graiciany de Paula Barros, G.P., Pereira, C., Veloso, M.A.F. and Costa, A.L. (2012) Study of an ADS Loaded with Thorium and Reprocessed Fuel. Science and Technology of Nuclear Installations, 2012, Article ID: 934105. https://doi.org/10.1155/2012/934105

[14] Pazirandeh, A. and Shirmohammadi, L. (2015) Simulation of an Accelerator Driven Subcritical Core with Mixed Uranium-Thorium Fuel. World Journal of Engineering and Technology, 3, 328-333. https://doi.org/10.4236/wjet.2015.33C049

[15] Gulik, V. and Tkaczyk, A.H. (2013) Optimization of Geometry, Material and Economic Parameters of a Two-Zone Subcritical Reactor for Transmutation of Nuclear 
Waste with SERPENT Monte Carlo Code. Proceedings of the Joint International Conference on Supercomputing in Nuclear Applications and Monte Carlo 2013, Paris, 14-21 October 2013, 01102. https://doi.org/10.1051/snamc/201401102

[16] Ballarini, F., Battistoni, G., Cerutti, F., Empl, A., Fassò, A., Ferrari, A., Gadioli, E., Garzelli, M.V., Ottolenghi, A., Pinsky, L.S., Ranft, J., Roesler, S., Sala, P.R. and Scannicchio, D. (2003) Nuclear Models in FLUKA: A Review. Proceedings of the 10th International Conference on Nuclear Reaction Mechanisms, Varenna, 9-13 June 2003. http://www0.mi.infn.it/ gadioli/proceedings/ferrari.ps

[17] National Research Council (US) Committee on Medical Isotope Production without Highly Enriched Uranium (2009) Medical Isotope Production without Highly Enriched Uranium: (Chap. 6) Molybdenum-99/Technetium-99m Production Costs. National Academies Press. https://www.ncbi.nlm.nih.gov/books/NBK215132 